C. Moliner, J. D. Badia, B. Bosio, E. Arato, T. Kittikorn, E. Strömberg, R. Teruel-Juanes, M. Ek, S. Karlsson \& A. Ribes-Greus (2018) Thermal and thermo-oxidative stability and kinetics of decomposition of PHBV/sisal composites, Chemical Engineering Communications, 205:2, 226-237

\title{
THERMAL AND THERMO-OXIDATIVE STABILITY AND KINETICS OF DECOMPOSITION OF PHBV/SISAL COMPOSITES
}

\author{
C.Moliner ${ }^{1,2}$, J.D. Badia ${ }^{2,3}$, B. Bosio ${ }^{1}$, E. Arato ${ }^{1}$, T. Kittikorn ${ }^{4,5}$, E. Strömberg ${ }^{4}$, R. Teruel-Juanes ${ }^{2}$, \\ M.Ek $^{4}$, S.Karlsson ${ }^{4,6}$, A.Ribes-Greus ${ }^{2, *}$
}

This is an open-access version, according to http://www.sherpa.ac.uk/romeo/issn/0098-6445/es/

Full text available at https://www.tandfonline.com/doi/abs/10.1080/00986445.2017.1384921

DOI: https://doi.org/10.1080/00986445.2017.1384921

Please, cite it as:

C. Moliner, J. D. Badia, B. Bosio, E. Arato, T. Kittikorn, E. Strömberg, R. Teruel-Juanes, M. Ek, S. Karlsson \& A. Ribes-Greus (2018) Thermal and thermo-oxidative stability and kinetics of decomposition of PHBV/sisal composites, Chemical Engineering Communications, 205:2, 226-237

\footnotetext{
${ }^{1}$ Dipartimento di Ingegneria Civile, Chimica e Ambientale (DICCA),Università degli Studi di Genova, Via Opera Pia 15,16145 Genova (Italy)

${ }^{2}$ Instituto de Tecnología de los Materiales (ITM), Universidad Politècnica de València (UPV) Camino de Vera S/N, 46022 Valencia, Spain.

${ }^{3}$ Departament d'Enginyeria Química. Escola Tècnica Superior d'Enginyeria. Universitat de València. Av. de la Universitat, s/n, 46100, Burjassot, Spain.

${ }^{4}$ School of Chemical Science and Engineering, Fibre and Polymer Technology, KTH - Royal Institute of Technology,

Teknikrigen 56-58, SE-10044 Stockholm, Sweden.

${ }^{5}$ Department of Materials Science and Technology, Faculty of Science, Prince of Songkla University Songkhla, 90112, Thailand.

*Corresponding author: A. Ribes-Greus aribes@ ter.upv.es
} 
C. Moliner, J. D. Badia, B. Bosio, E. Arato, T. Kittikorn, E. Strömberg, R. Teruel-Juanes, M. Ek, S. Karlsson \& A. Ribes-Greus

(2018) Thermal and thermo-oxidative stability and kinetics of decomposition of PHBV/sisal composites, Chemical Engineering Communications, 205:2, 226-237

\title{
THERMAL AND THERMO-OXIDATIVE STABILITY AND KINETICS OF DECOMPOSITION OF PHBV/SISAL COMPOSITES
}

C.Moliner ${ }^{1,2}$, J.D. Badia ${ }^{2,3}$, B. Bosio ${ }^{1}$, E. Arato ${ }^{1}$, T. Kittikorn ${ }^{4,5}$, E. Strömberg ${ }^{4}$, R. Teruel-Juanes ${ }^{2}$,

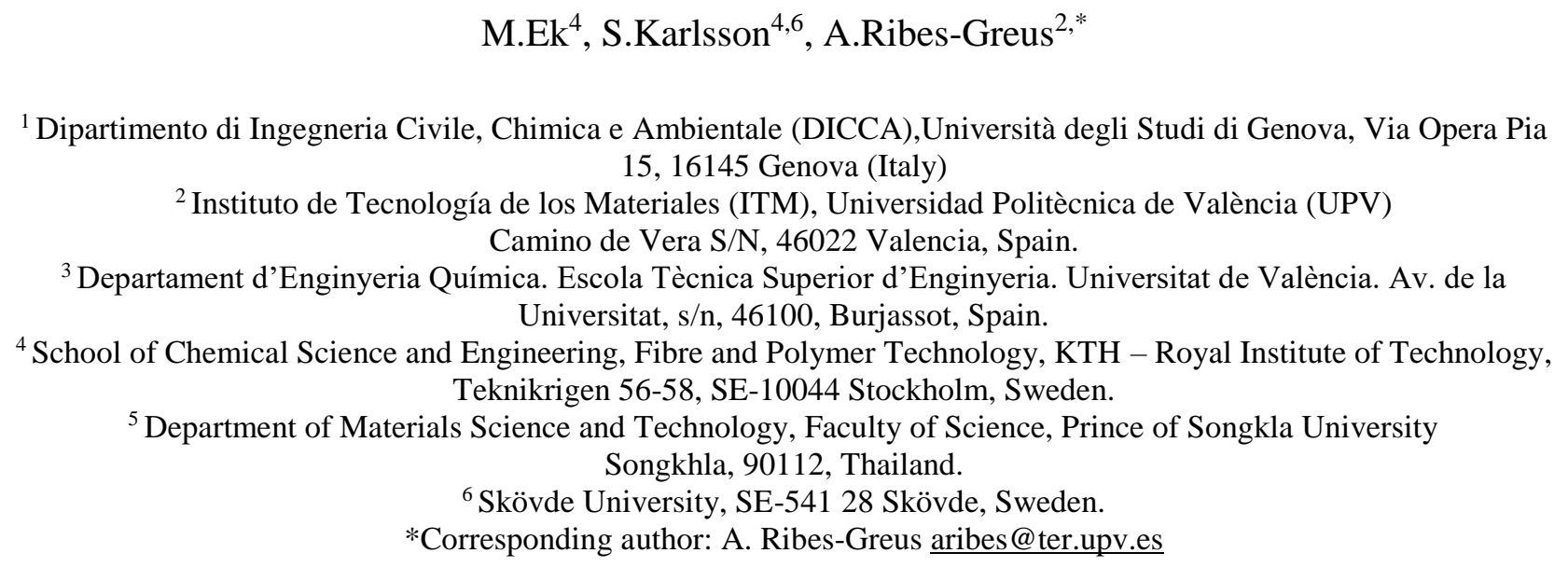

Keywords: biocomposites; poly(hydroxybutyrate-co-valerate) (PHBV); natural fibres; sisal; thermal decomposition; thermo-oxidative decomposition; kinetics; waste-to-fuel

\begin{abstract}
The decomposition behaviours of composites made of poly(3-hydroxybutyrate-co-3hydroxyvalerate) (PHBV) and sisal were assessed in terms of thermal stability and decomposition kinetics, under inert and oxidative conditions, by means of multi-rate linear non-isothermal thermogravimetric experiments. A Statistical Design of Experiments was applied to study the influence of the addition of sisal (0\%wt-30\%wt), the presence coupling agent (Yes/No) and the applied conditions of work (inert or oxidative). An improvement of the thermal and thermooxidative stability of PHBV with the addition of sisal was observed for all cases. An accurate methodology based on iso-conversional methods was applied to simulate the potential of thermal recovery technologies, such as pyrolysis and controlled combustion, to use these biocomposites after the end of their service life. The mathematical descriptions of both thermo-chemical reactions were helpful in the evaluation of the eventual optimal operational conditions to carry out a suitable energetic valorisation. A minimum of $240{ }^{\circ} \mathrm{C}$ and $137 \mathrm{~kJ} / \mathrm{mol}$ of activation energy in inert conditions and $236{ }^{\circ} \mathrm{C}$ and $118 \mathrm{~kJ} / \mathrm{mol}$ in oxidative conditions ensured the feasibility of the reactions regardless the composition of the PHBV/sisal biocomposites, which may ease the operability of further energy valorisation with the aim to turn biowaste into new fuels.
\end{abstract}


C. Moliner, J. D. Badia, B. Bosio, E. Arato, T. Kittikorn, E. Strömberg, R. Teruel-Juanes, M. Ek, S. Karlsson \& A. Ribes-Greus (2018) Thermal and thermo-oxidative stability and kinetics of decomposition of PHBV/sisal composites, Chemical Engineering Communications, 205:2, 226-237

\section{List of abbreviations and symbols}

Degree of conversion

Heating rate of thermogravimetric analysis $\left({ }^{\circ} \mathrm{C} / \mathrm{min}\right)$

$\square \mathrm{m}_{\mathrm{i}}$ Mass loss of the decomposition process i (\%)

A Pre-exponential factor

CA Coupling agent

DoE Design of Experiments

E Effect

Ea Apparent activation energy ( $\mathrm{J} / \mathrm{mol})$

$\mathrm{Ea}_{\text {iso }}$ Average apparent activation energy $(\mathrm{J} / \mathrm{mol})$

F Factor

FWO Flynn-Wall-Ozawa

KAS Kissinger-Akahira-Sunose

L Level

MEP Main effects plot

MP Master plots

$\mathrm{MP}_{\mathrm{f}, \mathrm{g}}$ Differential (f) and integral (g) form of MP

$\mathrm{n}$ Order in kinetic functions

PHBV Poly(3-hydroxybutyrate-co-3-hydroxyvalerate)

TG Thermogravimetric curve

TGA Thermogravimetric analysis

$\mathrm{T}_{\mathrm{pi}}$ Peak temperature of decomposition process $\mathrm{i}\left({ }^{\circ} \mathrm{C}\right)$

VYZ Vyazovkin 
C. Moliner, J. D. Badia, B. Bosio, E. Arato, T. Kittikorn, E. Strömberg, R. Teruel-Juanes, M. Ek, S. Karlsson \& A. Ribes-Greus (2018) Thermal and thermo-oxidative stability and kinetics of decomposition of PHBV/sisal composites, Chemical Engineering Communications, 205:2, 226-237

\section{Introduction}

The search of commercially viable green products based on natural resources for different applications is in continuous development. New obtaining routes to produce natural based goods with improved mechanical and thermal properties are being studied to obtain biodegradable products to be used as replacement of the current petroleum-based, non-biodegradable polymers, in many sectors such as automotive, household or packaging (Kowalczuk et al, 2014, Rydz et al, 2015).

These materials should be carefully managed when their service lives (Badia et al, 2014, Gil-Castell et al, 2014) are completed due to both exhaustion of performance or fast disposal of products with short-time uses, even with retained properties. Though bio-disposal facilities might be the logical step forward on waste management, the energetic options should be also considered (Al-Salem et al, 2009), taking into account that the accumulation of polymeric biowaste will potentially increase.

The application of thermo-chemical operations must be carefully evaluated when designing facilities for energy recovery purposes. In this sense, the study of the thermal and thermo-oxidative decomposition behaviours of materials stands out as the main basis for the correct tuning of the operation process. Thermogravimetric Analysis (TGA) is a widely used technique to assess the thermal stability and decomposition kinetics of biomass and biopolymers.

Among all the biopolymers produced from renewable resources, polyhydroxyalkanoates (PHAs) have a very wide range of properties and applications (Weng et al, 2010, Bledzki et al, 2010). Poly (3-hydroxybutyrate-co-3-hydroxyvalerate) (PHBV) is among the most popular PHAs which, despite its biodegradability and biocompatibility, presents a low strength impact which makes it non suitable for determined technical applications. In order to improve its mechanical properties, reinforcing agents can be added to the polymeric matrix. Materials such as wood or natural fibres are commonly used to reinforce thermoplastics due to their low cost, abundant availability, high performance and low density (Fernandez et al, 2004). In this sense, the study of the thermochemical properties of the new biocomposites constitutes a first essential step to evaluate the influence of the addition of reinforcements and coupling agents on the main operational parameters of the energy recovery facilities. 
C. Moliner, J. D. Badia, B. Bosio, E. Arato, T. Kittikorn, E. Strömberg, R. Teruel-Juanes, M. Ek, S. Karlsson \& A. Ribes-Greus (2018) Thermal and thermo-oxidative stability and kinetics of decomposition of PHBV/sisal composites, Chemical Engineering Communications, 205:2, 226-237

Within this framework, the aim of this work was to obtain useful parameters that characterise the thermal properties of PHBV and its biocomposites during their life service and also for eventual energy recovery processes once the compounds achieve their end of life. In particular, the influence of the addition of sisal fibres and a coupling agent on the thermal and thermo-oxidative stability and on the decomposition kinetics of PHBV biocomposites was evaluated in detail and, based on the results, an optimal range of operational conditions was proposed.

\section{Experimental procedure}

\subsection{Materials and sample preparation.}

Poly (3-hydroxybutyrate-co-3-hydroxyvalerate) (PHBV) ENMAT Y1000P was obtained from Tianan Biologic (China). Sisal fibre was supplied by Thai Royal project (Thailand). Maleic anhydride (MA) 98\% of purity (Fluka) and dicumyl peroxide (DCP) 98\% of purity (Sigma Aldrich) were used as coupling agent and free radical initiator, respectively. Processing of biocomposites was detailed in a previous work (Badia et al. 2014). Shortly, the samples were processed to obtain biocomposites with 10\%, 20\% and 30\% in weight of sisal fibers, a $2.5 \%$ wt MA and $0.3 \%$ wt of DCP. All materials were mixed in an internal mixer (Brabender, Germany) during 5 min at $180{ }^{\circ} \mathrm{C}$ and $50 \mathrm{rpm}$ of speed and subsequently ground and pressed by compression moulding (Fontijne Presses, Holland) into $0.5 \mathrm{~mm}$ thick plates, used as specimens. The biocomposites were labelled as PHBV\%fCA, being PHBV the polymeric matrix, \%f the percentage of fibre in the biocomposite and CA the indication of using coupling agent in the formulation.

\subsection{Thermogravimetric analyses}

Multi-rate non-isothermal linear thermogravimetric experiments (TGA) were carried out in a Mettler Toledo TGA/SDTA 851 (Columbus, OH). Samples weighing around $7 \mathrm{mg}$ were heated in an alumina holder with capacity for $70 \square \mathrm{L}$. Experiments were performed from $25^{\circ} \mathrm{C}$ to $750{ }^{\circ} \mathrm{C}$ at different heating rates $\left(\square=2,5,7,10,12,15^{\circ} \mathrm{C} / \mathrm{min}\right)$ under constant flow of $50 \mathrm{~mL} \cdot \mathrm{min}^{-1}$ of gas of analysis.

All samples were analysed under inert $(\mathrm{Ar})$ and oxidative $\left(\mathrm{O}_{2}\right)$ atmospheres to characterise the thermal and thermo-oxidative processes, respectively. Experiments were repeated at least three times and the averages were considered as representative values. 


\subsection{Statistical Assessment}

A statistical assessment based on the factorial analysis of the Design of Experiments (DoE) is an efficient procedure for planning experiments as it is based on the study of the influence of multiple input variables (Factors, F) that can be varied (Levels, L) to obtain the response variable (Effect, E). Any combination of $\mathrm{F}$ and $\mathrm{L}$ corresponds to a run in a practical experimentation. $\mathrm{F}$ can be quantitative (categorical variable) or qualitative (based on a continuous variable). Each $\mathrm{F}$ must have two or more settings (L) so that the $\mathrm{E}$ of the change of $\mathrm{L}$ can be assessed on the response (Badia et al, 2011a, 2011b).

The individual influence of each $\mathrm{F}$ through the different $\mathrm{L}$ was analyzed by means of Main Effect Plots (MEP). The Factors/Levels under consideration were (i) fiber amount (\%) / 0, 10, 20, 30; (ii) use of coupling agent / NO, YES; and (iii) atmosphere of analysis / $\mathrm{Ar}, \mathrm{O}_{2}$. The Effects chosen for the analysis were the experimental outputs of characteristic temperatures and mass losses. These results can not only lead to an optimisation of the experimental conditions of a given process but also to the understanding of the effect of each factor at different levels to the final response.

\section{Results and discussion}

\subsection{Description of Thermal and Thermo-oxidative decomposition profiles}

The thermal performance of PHBV and its composites was initially addressed. The thermogravimetric curves (TG) were obtained for each biocomposite at all heating rates $\beta$ under inert and oxidative atmosphere. Fig. 1 represents the thermograms of PHBV (Fig. 1a) and PHBV30CA (Fig. 1b) for all $\beta$ under inert ambient. Similar curves were shown by the rest of biocomposites whose curves lay between both thermograms. As expected, higher $\beta$ shifted the thermograms to higher temperatures. 
C. Moliner, J. D. Badia, B. Bosio, E. Arato, T. Kittikorn, E. Strömberg, R. Teruel-Juanes, M. Ek, S. Karlsson \& A. Ribes-Greus (2018) Thermal and thermo-oxidative stability and kinetics of decomposition of PHBV/sisal composites, Chemical Engineering Communications, 205:2, 226-237
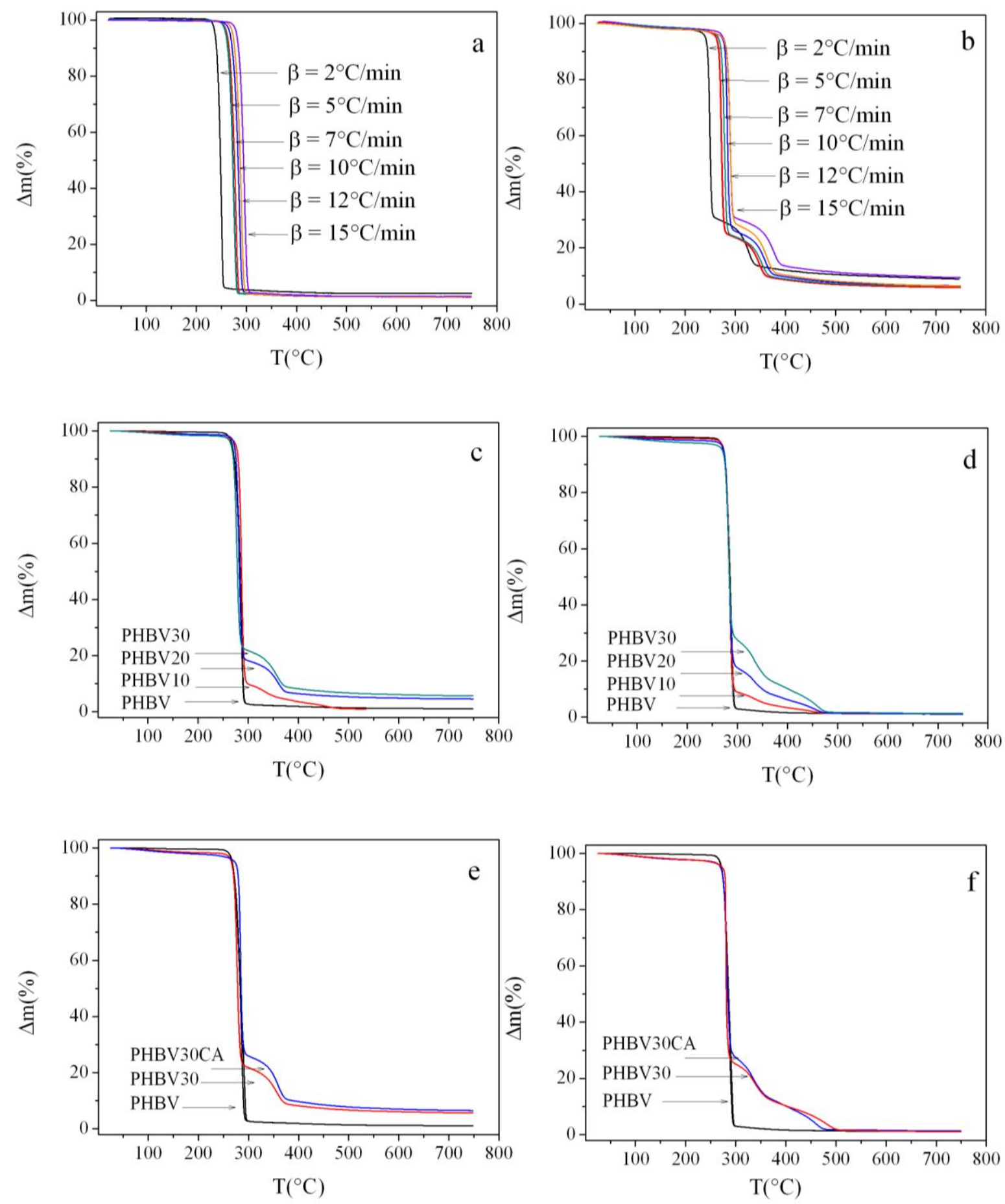

Fig. 1 Thermogravimetric (TG) curves for PHBV (a) and PHBV30CA (b) for all $\beta$ at inert atmosphere; TG curve at $\square=10^{\circ} \mathrm{C} / \mathrm{min}$ for PHBV and the corresponding composites, under both inert (c) and oxidative (d) atmospheres; Influence of the addition of CA on the decomposition of PHBV biocomposites under both inert (e) and oxidative (f) atmospheres. 
C. Moliner, J. D. Badia, B. Bosio, E. Arato, T. Kittikorn, E. Strömberg, R. Teruel-Juanes, M. Ek, S. Karlsson \& A. Ribes-Greus (2018) Thermal and thermo-oxidative stability and kinetics of decomposition of PHBV/sisal composites, Chemical Engineering Communications, 205:2, 226-237

Fig. 1 also shows the TG curve at $\square=10^{\circ} \mathrm{C} / \mathrm{min}$ for PHBV and the corresponding biocomposites under both inert (Fig. 1c) and oxidative (Fig. 1d) atmosphere. The thermal decomposition (TD) of the polymeric matrix without any fibre in its composition (PHBV) occurred through one single step decay. After a thermostable range, the material started to decompose at around $300{ }^{\circ} \mathrm{C}$, consuming almost the majority of the initial mass. The addition of natural fibres to the polymeric matrix resulted in an increase of the observed number of decomposition stages with respect to the polymeric matrix in all cases.

Indeed, the decomposition of the biocomposites was influenced by the applied atmosphere showing a two-step mass-loss process under inert conditions and a three-step mass-loss process for the case of an oxidative atmosphere:

- The first step of the decomposition occurred at around $300{ }^{\circ} \mathrm{C}$ for neat PHBV and all $\mathrm{PHBV} /$ sisal biocomposites under both atmospheres. A decrease of the mass loss associated to this process $\left(\Delta \mathrm{m}_{1}\right)$ was observed with the increase of the percentage of natural fibres in the biocomposites. Therefore, this mass-loss step is ascribed to the decomposition of the PHBV matrix.

- The second step started at around $400{ }^{\circ} \mathrm{C}$ under both atmospheres, eliminating an increasing quantity of mass $\left(\Delta \mathrm{m}_{2}\right)$ with the increasing quantity of fibre in the matrix. Thus, this second step was related to the decomposition of the fibre, in agreement with literature (Moran et al, 2008). Sisal is a natural fibre mainly composed by cellulose $(70 \%)$, hemicellulose $(20 \%)$ and lignin $(6 \%)$. The main decomposition process of cellulose takes place at around $400{ }^{\circ} \mathrm{C}$ confirming the assignation of the second peak to the fibre decomposition.

- Finally, a third step was observed only for the case of oxidative reactions that could be assigned to char and to the further breakage of the decomposition products from the previous step (Monteiro et al, 2012). Despite the mechanism of decomposition is complex, it is related to the same component and, therefore, the second and third decomposition processes observed under oxidative conditions were considered as one single step for mathematical purposes. 
C. Moliner, J. D. Badia, B. Bosio, E. Arato, T. Kittikorn, E. Strömberg, R. Teruel-Juanes, M. Ek, S. Karlsson \& A. Ribes-Greus (2018) Thermal and thermo-oxidative stability and kinetics of decomposition of PHBV/sisal composites, Chemical Engineering Communications, 205:2, 226-237

The influence of the presence of coupling agent in the biocomposites is shown at the TG profiles in Fig. 1, for the case of inert (Fig. 1e) and oxidative (Fig. 1f) atmospheres. The addition of coupling agent to the polymeric matrix resulted in an increase on the thermal stability of the biocomposites in all cases due to the formation of stronger chemical bonds between the matrix and the fibre (Lu et al, 2000), with a more significant effect under inert conditions, as shown in the next section.

\subsection{Assessment of the thermal and thermo-oxidative stability of the biocomposites}

The thermal behaviour evaluation of the biocomposites is a key aspect for, in the first instance, the assurance of the complete properties of the bioplastics if processed and transformed to become a new product (ie. during extrusion processes) and, once their life service is over, the definition of the most adequate operational parameters to carry out potential energy recovery reactions.

With the aim of individually define the decomposition processes, a deconvolution procedure was applied to all samples following the methodology explained elsewhere (Badia et al, 2010). An example of the original DTG curve (black line) for PHBV30 and the resulting deconvoluted ones (red and grey circles) are shown in Fig. 2 for inert conditions.

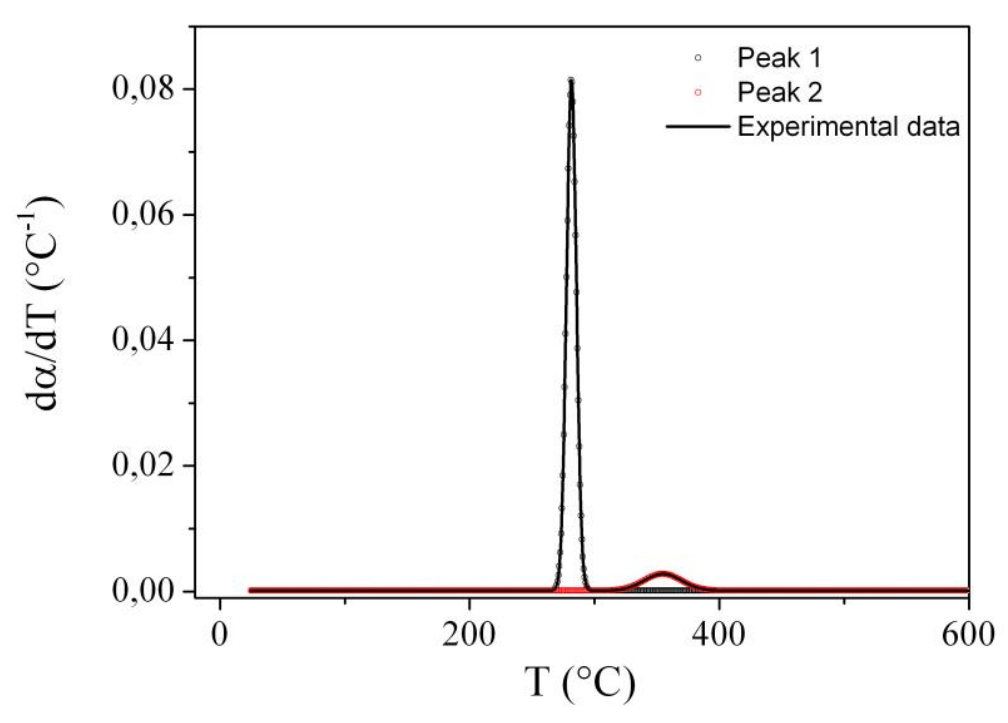

Fig. 2 Experimental data (DTG) and deconvoluted curves for the sample PHBV30 under inert conditions 
C. Moliner, J. D. Badia, B. Bosio, E. Arato, T. Kittikorn, E. Strömberg, R. Teruel-Juanes, M. Ek, S. Karlsson \& A. Ribes-Greus (2018) Thermal and thermo-oxidative stability and kinetics of decomposition of PHBV/sisal composites, Chemical Engineering Communications, 205:2, 226-237

A statistical evaluation of the thermal properties of all samples has been performed in order to study the effect of the addition of fibres on the main thermal parameters, as well as the effect of the addition of CA and the application of inert or oxidative conditions.

With the aim of evaluating the thermal stability of PHBV and its biocomposites under both of the atmospheres $\left(\mathrm{Ar}\right.$ and $\left.\mathrm{O}_{2}\right)$, the corresponding decomposition onset $\left(\mathrm{T}_{0}\right)$ and endset $\left(\mathrm{T}_{\mathrm{e}}\right)$ temperatures were obtained by a tangential method onto the TG curves for all samples (Table 1). These parameters were studied for $\square=2{ }^{\circ} \mathrm{C} / \mathrm{min}$, where the phenomena of thermal inertia are minimised and so, the values represent more accurately the real temperatures of the samples. The peak temperatures of the first-derivative thermogravimetric curves (DTG) of all the observed processes $\left(\mathrm{T}_{\mathrm{p} 1}, \mathrm{~T}_{\mathrm{p} 2}\right)$ and their associated mass loss $\left(\square \mathrm{m}_{1}, \square \mathrm{m}_{2}\right)$ were also calculated at all heating rates $\square$ and are gathered in Table 2 and 3 respectively together with the values of the remaining residue.

Table 1. Characteristic temperatures $\left(\mathrm{T}_{0}, \mathrm{~T}_{\mathrm{e}}\right)$ and $\square \mathrm{T}$ for PHBV/Sisal biocomposites $\left(\mathrm{Ar}-\mathrm{O}_{2}\right)$ at $2{ }^{\circ} \mathrm{C} / \mathrm{min}$ )

\begin{tabular}{|c|c|c|c|c|c|c|c|c|c|c|}
\hline & \multicolumn{5}{|c|}{ Ar } & \multicolumn{5}{|c|}{$\mathbf{O}_{2}$} \\
\hline Material & $\mathrm{T}_{0}\left({ }^{\circ} \mathrm{C}\right)$ & e $(\%)$ & $\mathbf{T}_{\mathrm{e}}\left({ }^{\circ} \mathbf{C}\right)$ & e $(\%)$ & $\square \mathbf{T}\left({ }^{\circ} \mathbf{C}\right)$ & $\mathrm{T}_{0}\left({ }^{\circ} \mathrm{C}\right)$ & e $(\%)$ & $T_{e}\left({ }^{\circ} \mathrm{C}\right)$ & e $(\%)$ & $\square \mathbf{T}\left({ }^{\circ} \mathbf{C}\right)$ \\
\hline PHBV & 231 & $\pm 4,0$ & 305 & $\pm 3,1$ & 74 & 220 & $\pm 0,2$ & 306 & $\pm 0,6$ & 86 \\
\hline PHBV10 & 224 & $\pm 2,7$ & 375 & $\pm 1,6$ & 151 & 222 & $\pm 0,2$ & 370 & $\pm 0,8$ & 148 \\
\hline PHBV20 & 238 & $\pm 0,6$ & 386 & $\pm 0,7$ & 148 & 228 & $\pm 0,4$ & 365 & $\pm 0,7$ & 137 \\
\hline PHBV30 & 239 & $\pm 0,1$ & 382 & $\pm 0,3$ & 143 & 225 & $\pm 1,0$ & 370 & $\pm 0,6$ & 145 \\
\hline PHBV10CA & 230 & $\pm 3,6$ & 377 & $\pm 3,3$ & 147 & 225 & $\pm 0,2$ & 362 & $\pm 0,4$ & 137 \\
\hline PHBV20CA & 238 & $\pm 0,1$ & 380 & $\pm 0,5$ & 142 & 230 & $\pm 0,3$ & 367 & $\pm 0,7$ & 137 \\
\hline PHBV30CA & 240 & $\pm 0,2$ & 379 & $\pm 0,1$ & 139 & 236 & $\pm 0,9$ & 365 & $\pm 1,1$ & 129 \\
\hline
\end{tabular}

In terms of design, $\mathrm{T}_{0}$ is associated to suitable safety margins related to the thermal and thermooxidative stability of the biocomposites whereas $T_{p 1}$ and $T_{p 2}$ provide the minimum temperature of work required in the reactor to reach the maximum velocity of decomposition of their associated stages.

Generally, $\mathrm{T}_{0}$ increased with the addition of natural fibres to the polymeric matrix which also resulted in an extended range of decomposition (ie. increase of $\square \mathrm{T}$ with $\square \mathrm{T}=\mathrm{T}_{\mathrm{e}}-\mathrm{T}_{0}$ ). Also, the addition of coupling agent resulted in a slight increase of the thermal stability of all the biocomposites, indicating an improved fibre-matrix interaction. 
C. Moliner, J. D. Badia, B. Bosio, E. Arato, T. Kittikorn, E. Strömberg, R. Teruel-Juanes, M. Ek, S. Karlsson \& A. Ribes-Greus (2018) Thermal and thermo-oxidative stability and kinetics of decomposition of PHBV/sisal composites, Chemical Engineering Communications, 205:2, 226-237

Table 2. Characteristic temperatures $\left(\mathrm{T}_{\mathrm{p} 1}, \mathrm{~T}_{\mathrm{p} 2}\right)$ for PHBV/Sisal biocomposites $\left(\mathrm{Ar}_{-} \mathrm{O}_{2}\right)(2,5$, $\left.10,15^{\circ} \mathrm{C} / \mathrm{min}\right)$

\begin{tabular}{|c|c|c|c|c|c|c|c|c|c|}
\hline & & \multicolumn{4}{|c|}{ Ar } & \multicolumn{4}{|c|}{$\mathbf{O}_{2}$} \\
\hline & Material & $\mathbf{T}_{\mathrm{p} 1}\left({ }^{\circ} \mathbf{C}\right)$ & e $(\%)$ & $\mathbf{T}_{\mathrm{p} 2}\left({ }^{\circ} \mathbf{C}\right)$ & e $(\%)$ & $\mathbf{T}_{\mathbf{p} 1}\left({ }^{\mathbf{o}} \mathbf{C}\right)$ & e $(\%)$ & $\mathbf{T}_{\mathbf{p} 2}\left({ }^{\circ} \mathbf{C}\right)$ & e $(\%)$ \\
\hline \multirow{8}{*}{$2^{\circ} \mathrm{C} / \mathrm{min}$} & PHBV & 244 & $\pm 3,4$ & - & - & 259 & $\pm 0,4$ & - & - \\
\hline & PHBV10 & 244 & $\pm 2,1$ & 328 & $\pm 0,2$ & 256 & $\pm 0,6$ & 305 & $\pm 0,5$ \\
\hline & PHBV20 & 248 & $\pm 0,4$ & 327 & $\pm 0,4$ & 252 & $\pm 0,7$ & 306 & $\pm 0,3$ \\
\hline & PHBV30 & 246 & $\pm 0,2$ & 323 & $\pm 1,8$ & 254 & $\pm 0,7$ & 305 & $\pm 0,1$ \\
\hline & PHBV10CA & 245 & $\pm 3,3$ & 324 & $\pm 0,9$ & 260 & $\pm 0,3$ & 305 & $\pm 0,1$ \\
\hline & PHBV20CA & 251 & $\pm 0,2$ & 317 & $\pm 2,5$ & 259 & $\pm 0,2$ & 304 & $\pm 0,3$ \\
\hline & PHBV30CA & 250 & $\pm 0,2$ & 326 & $\pm 0,2$ & 259 & $\pm 0,9$ & 305 & $\pm 0,1$ \\
\hline & Material & $\mathrm{T}_{\mathrm{p} 1}\left({ }^{\circ} \mathrm{C}\right)$ & e $(\%)$ & $\mathrm{T}_{\mathrm{p} 2}\left({ }^{\circ} \mathrm{C}\right)$ & e $(\%)$ & $\mathrm{T}_{\mathrm{p} 1}\left({ }^{\circ} \mathrm{C}\right)$ & e (\%) & $\mathrm{T}_{\mathrm{p} 2}\left({ }^{\circ} \mathrm{C}\right)$ & e $(\%)$ \\
\hline \multirow{8}{*}{$5^{\circ} \mathrm{C} / \min$} & PHBV & 273 & $\pm 0,3$ & - & - & 277 & $\pm 0,3$ & - & - \\
\hline & PHBV10 & 270 & $\pm 0,4$ & 347 & $\pm 0,5$ & 275 & $\pm 0,1$ & 320 & $\pm 0,4$ \\
\hline & PHBV20 & 269 & $\pm 0,1$ & 348 & $\pm 0,1$ & 273 & $\pm 0,3$ & 320 & $\pm 0,2$ \\
\hline & PHBV30 & 264 & $\pm 0,9$ & 349 & $\pm 0,1$ & 273 & $\pm 0,1$ & 322 & $\pm 0,1$ \\
\hline & PHBV10CA & 274 & $\pm 0,2$ & 348 & $\pm 0,1$ & 277 & $\pm 0,2$ & 320 & $\pm 0,3$ \\
\hline & PHBV20CA & 271 & $\pm 0,2$ & 346 & $\pm 0,3$ & 279 & $\pm 0,1$ & 321 & $\pm 0,2$ \\
\hline & PHBV30CA & 272 & $\pm 0,1$ & 348 & $\pm 0,1$ & 278 & $\pm 0,1$ & 322 & $\pm 0,1$ \\
\hline & Material & $\mathrm{T}_{\mathrm{p} 1}\left({ }^{\circ} \mathrm{C}\right)$ & e $(\%)$ & $\mathrm{T}_{\mathrm{p} 2}\left({ }^{\circ} \mathrm{C}\right)$ & e (\%) & $\mathrm{T}_{\mathrm{p} 1}\left({ }^{\circ} \mathrm{C}\right)$ & e (\%) & $\mathrm{T}_{\mathrm{p} 2}\left({ }^{\circ} \mathrm{C}\right)$ & e (\%) \\
\hline \multirow{8}{*}{$10^{\circ} \mathrm{C} / \mathrm{min}$} & PHBV & 283 & $\pm 0,1$ & - & - & 283 & $\pm 0,6$ & - & - \\
\hline & PHBV10 & 281 & $\pm 0,2$ & 359 & $\pm 0,4$ & 281 & $\pm 0,4$ & 323 & $\pm 4,3$ \\
\hline & PHBV20 & 280 & $\pm 0,4$ & 359 & $\pm 0,2$ & 282 & $\pm 0,2$ & 335 & $\pm 0,1$ \\
\hline & PHBV30 & 277 & $\pm 0,3$ & 359 & $\pm 0,4$ & 281 & $\pm 0,1$ & 334 & $\pm 0,2$ \\
\hline & PHBV10CA & 281 & $\pm 1,7$ & 357 & $\pm 0,4$ & 282 & $\pm 0,2$ & 335 & $\pm 0,1$ \\
\hline & PHBV20CA & 282 & $\pm 0,4$ & 357 & $\pm 0,3$ & 285 & $\pm 0,3$ & 335 & $\pm 0,2$ \\
\hline & PHBV30CA & 283 & $\pm 0,1$ & 359 & $\pm 0,2$ & 288 & $\pm 0,7$ & 339 & $\pm 0,1$ \\
\hline & Material & $\mathrm{T}_{\mathrm{p} 1}\left({ }^{\circ} \mathrm{C}\right)$ & e (\%) & $\mathrm{T}_{\mathrm{p} 2}\left({ }^{\circ} \mathrm{C}\right)$ & e $(\%)$ & $\mathrm{T}_{\mathrm{p} 1}\left({ }^{\circ} \mathrm{C}\right)$ & e (\%) & $\mathrm{T}_{\mathrm{p} 2}\left({ }^{\circ} \mathrm{C}\right)$ & e $(\%)$ \\
\hline \multirow{7}{*}{$15^{\circ} \mathrm{C} / \mathrm{min}$} & PHBV & 292 & $\pm 0,7$ & - & - & 292 & $\pm 0,2$ & - & - \\
\hline & PHBV10 & 289 & $\pm 0,1$ & 365 & $\pm 0,2$ & 291 & $\pm 0,2$ & 343 & $\pm 0,2$ \\
\hline & PHBV20 & 287 & $\pm 0,2$ & 367 & $\pm 0,2$ & 290 & $\pm 0,1$ & 344 & $\pm 0,2$ \\
\hline & PHBV30 & 288 & $\pm 0,9$ & 366 & $\pm 0,1$ & 289 & $\pm 0,4$ & 345 & $\pm 0,2$ \\
\hline & PHBV10CA & 293 & $\pm 0,3$ & 364 & $\pm 0,2$ & 294 & $\pm 0,1$ & 342 & $\pm 0,2$ \\
\hline & PHBV20CA & 291 & $\pm 0,3$ & 366 & $\pm 0,1$ & 294 & $\pm 0,3$ & 344 & $\pm 0,1$ \\
\hline & PHBV30CA & 293 & $\pm 0,1$ & 363 & $\pm 0,1$ & 291 & $\pm 0,1$ & 346 & $\pm 0,2$ \\
\hline
\end{tabular}


C. Moliner, J. D. Badia, B. Bosio, E. Arato, T. Kittikorn, E. Strömberg, R. Teruel-Juanes, M. Ek, S. Karlsson \& A. Ribes-Greus (2018) Thermal and thermo-oxidative stability and kinetics of decomposition of PHBV/sisal composites, Chemical Engineering Communications, 205:2, 226-237

Table 3. Averaged associated mas loss $\left(\square \mathrm{m}_{1}, \square \mathrm{m}_{2}\right)$ and remaining residue for PHBV/Sisal biocomposites $\left(\mathrm{Ar}-\mathrm{O}_{2}\right)$ at $\square=2^{\circ} \mathrm{C} / \mathrm{min}$

\begin{tabular}{|c|c|c|c|c|c|c|c|c|c|c|}
\hline & \multicolumn{5}{|c|}{ Ar } & \multicolumn{5}{|c|}{$\mathrm{O}_{2}$} \\
\hline Material & $\begin{array}{l}\square \mathbf{m}_{1} \\
(\boldsymbol{\%})\end{array}$ & e (\%) & $\square \mathbf{m}_{2}(\%)$ & e (\%) & $\operatorname{Res}(\%)$ & $\begin{array}{l}\square \mathbf{m}_{1} \\
(\boldsymbol{\%})\end{array}$ & e $(\%)$ & $\begin{array}{l}\square \mathbf{m}_{2} \\
(\%)\end{array}$ & e $(\%)$ & $\operatorname{Res}(\%)$ \\
\hline PHBV & 98,5 & $\pm 1,5$ & - & - & 1,5 & 99,3 & $\pm 0,05$ & - & - & 0,7 \\
\hline PHBV10 & 87,0 & $\pm 2,0$ & 10,5 & $\pm 1,5$ & 2,5 & 87,0 & $\pm 2,0$ & 12,2 & $\pm 0,4$ & 0,8 \\
\hline PHBV20 & 81,0 & $\pm 1,2$ & 14,6 & $\pm 1,5$ & 4,4 & 79,5 & $\pm 0,5$ & 18,8 & $\pm 0,3$ & 1,7 \\
\hline PHBV30 & 75,0 & $\pm 2,5$ & 19,4 & $\pm 2,0$ & 5,6 & 75,0 & $\pm 1,0$ & 22,0 & $\pm 0,6$ & 3,0 \\
\hline PHBV10CA & 86,7 & $\pm 0,6$ & 10,3 & $\pm 0,7$ & 3,0 & 86,5 & $\pm 0,5$ & 11,8 & $\pm 0,2$ & 1,7 \\
\hline PHBV20CA & 77,2 & $\pm 1,3$ & 18,3 & $\pm 0,5$ & 4,5 & 82,0 & $\pm 0,7$ & 16,0 & $\pm 0,3$ & 2,0 \\
\hline PHBV30CA & 74,0 & $\pm 1,0$ & 19,5 & $\pm 0,4$ & 6,5 & 73,5 & $\pm 3,0$ & 23,4 & $\pm 1,4$ & 3,1 \\
\hline
\end{tabular}

The variation of the atmosphere of work showed that $\mathrm{T}_{0}$ presented lower values for reactions under $\mathrm{O}_{2}$ indicating, as expected, a lower stability of the initial polymeric matrix under oxidative conditions due to a more reactive conditions of work.

It is worth noting that $\mathrm{T}_{0}$ is notably higher than the melting temperature of PHBV $\left(\mathrm{T}_{\mathrm{m}}=150{ }^{\circ} \mathrm{C}\right)^{1}$. This fact ensures the processing of the polymers without degrading the compounds and also, might permit further reprocessing processes maintaining their properties.

As seen in Table 2, the polymeric matrix decomposed before the natural fibre in all samples. Also, as expected, all the compounds decomposed at the maximum velocity at lower temperatures in oxidative conditions as a result of an increased reactivity in the system.

From Table 3 and regarding the residue values, under inert conditions, the addition of fibres resulted in increased residue percentages whereas pure PHBV decomposed almost completely confirming that the fibres were less affected to inert atmospheres. The addition of CA slightly increased the residue values respect to the samples without its presence. Oxidative conditions provided lower residual percentages, with a maximum value of $3 \%$ suggesting that the biopolymers were highly affected by oxidative reactions.

Fig. 3 shows the Main Effect Plots (MEP) of the DoE for the response variables $\mathrm{T}_{0}$ (a) and $\Delta \mathrm{m}_{1}$ and $\Delta \mathrm{m}_{2}$ (b). The changes in the level means provided information concerning the factors that influenced the response the most:

\footnotetext{
${ }^{1}$ (http://www.ecojo.co.il/images/pdf/rawmaterials/ENMAT_Y1000_Technical_Data_Sheet.pdf)
} 
C. Moliner, J. D. Badia, B. Bosio, E. Arato, T. Kittikorn, E. Strömberg, R. Teruel-Juanes, M. Ek, S. Karlsson \& A. Ribes-Greus (2018) Thermal and thermo-oxidative stability and kinetics of decomposition of PHBV/sisal composites, Chemical Engineering Communications, 205:2, 226-237

- As it can be suggested from Fig 3a, the thermal stability was mostly affected by the percentage of natural fibres in the polymer matrix. The same trend was seen for $\Delta \mathrm{m}_{1}$ and $\Delta \mathrm{m}_{2}$ (Fig 3b) confirming the previous hypothesis relating the first stage of decomposition $\left(\Delta \mathrm{m}_{1}\right)$ to the principal backbone and the second $\left(\Delta \mathrm{m}_{2}\right)$ to the decomposition of the natural fibers.

- The addition of coupling agent CA to the samples improved the thermal stability of the biocomposites, as $\mathrm{T}_{0}$ increased with the presence of $\mathrm{CA}$ which also confirmed the previously suggested hypothesis whereas it was no relevant for $\Delta \mathrm{m}_{1}$ and $\Delta \mathrm{m}_{2}$.

- Regarding the influence of the atmosphere of work, $\mathrm{T}_{0}$ presented lower values for oxidative conditions indicating that the trigger of decomposition was more sensitive to oxidant reactions.
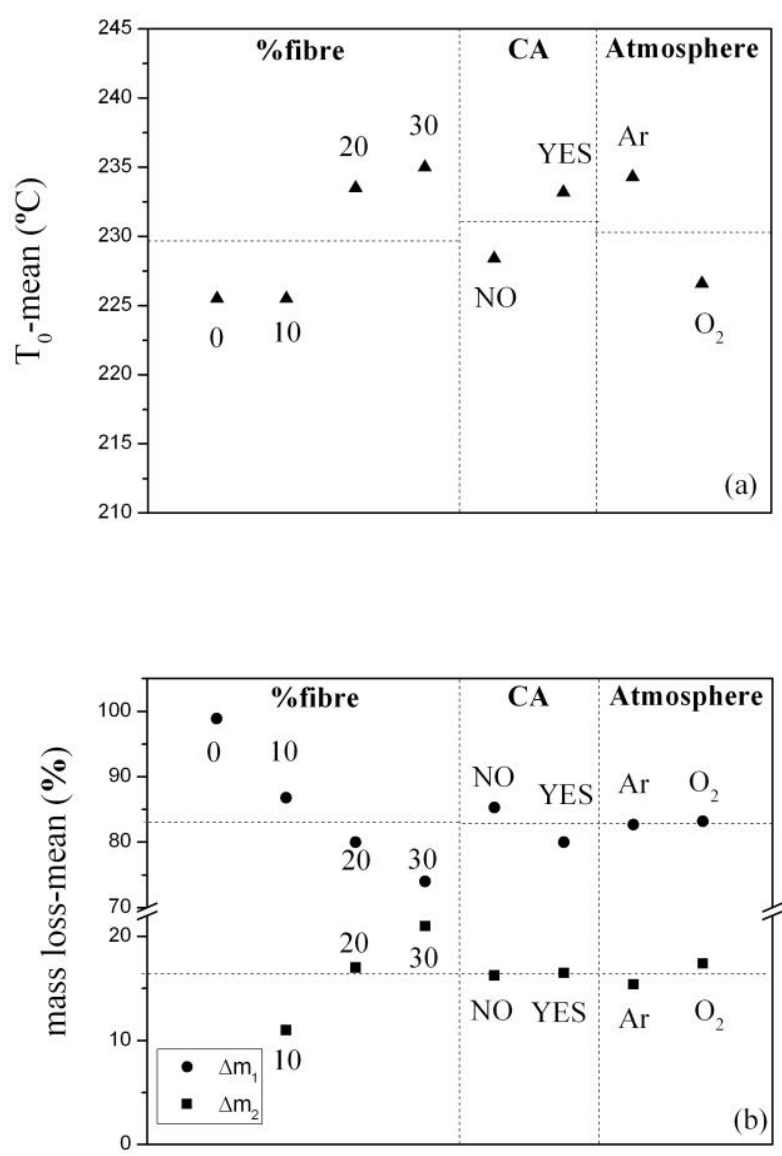

Fig. 3 Main Effect Plots (MEP) of the DoE for the variables temperature of decomposition - $\mathrm{T}_{0}$ (a) and mass loss - $\square \mathrm{m}_{\mathrm{i}}$ (b) 
C. Moliner, J. D. Badia, B. Bosio, E. Arato, T. Kittikorn, E. Strömberg, R. Teruel-Juanes, M. Ek, S. Karlsson \& A. Ribes-Greus (2018) Thermal and thermo-oxidative stability and kinetics of decomposition of PHBV/sisal composites, Chemical Engineering Communications, 205:2, 226-237

\subsection{Kinetic triplet defining the thermal and thermo-oxidative decomposition kinetics}

As stated before, the study of the kinetics of decomposition is an essential step to define the correct performance of a device aimed to perform thermo-chemical reactions. Several simulation works are performed assuming equilibrium conditions but, the implementation of the exact kinetic law would provide more accurate results and would help improving the optimization of energy recovery processes.

The kinetic law is defined by three characteristic parameters: apparent activation energy (Ea), preexponential factor (A) and mechanism and order of reaction ( $f(\square), n)$, forming the so-called kinetic triplet, following Eq. (1):

$$
\frac{d \alpha}{d t} \equiv \beta \cdot \frac{d \alpha}{d T}=A \cdot f(\alpha) \cdot k(T)=A \cdot f(\alpha) \cdot e^{\frac{-E_{a}}{R \cdot T}}
$$

For this work, the kinetic triplet of the main decomposition process (corresponding to the polymeric backbone) was calculated through the application of the method described elsewhere (Badia et al, 2012a, 2012b, Moliner et al, 2016) to the previously deconvoluted curves.

\subsubsection{Apparent activation energies}

The isoconversional methods Flynn-Wall-Ozawa (FWO) (Flyn, Wall, 1966, Ozawa, 1970), Kissinger-Akahira-Sunose (KAS) (Akahira-Sunose, 1971) and Vyazovkin (VYZ) (Vyazovkin, 1997) were applied as shown elsewhere (Badia et al, 2013) to evaluate the dependence of the apparent activation energy $\left(\mathrm{Ea}_{\alpha}\right)$ with the conversion degree of the reaction $\alpha=\left(m_{0}-m_{i}\right) /\left(m_{0}-m_{\infty}\right) \square \square$ where $m$ is the mass with the subscripts $0, \mathrm{i}$ and $\infty$ standing for initial, instant and final respectively).

Fig. 4 shows an example of the application of the KAS method for the different tested specimens under inert (a) and oxidative (b) conditions. As seen in Fig 4a, Ea remained constant for all whereas the presence of oxygen resulted in an increase of the oxidant reactions taking place and therefore, in less constant trend. However, the associated error values were still narrow enough to consider them constant during the interval of study (Badia et al, 2013). 
C. Moliner, J. D. Badia, B. Bosio, E. Arato, T. Kittikorn, E. Strömberg, R. Teruel-Juanes, M. Ek, S. Karlsson \& A. Ribes-Greus (2018) Thermal and thermo-oxidative stability and kinetics of decomposition of PHBV/sisal composites, Chemical Engineering Communications, 205:2, 226-237
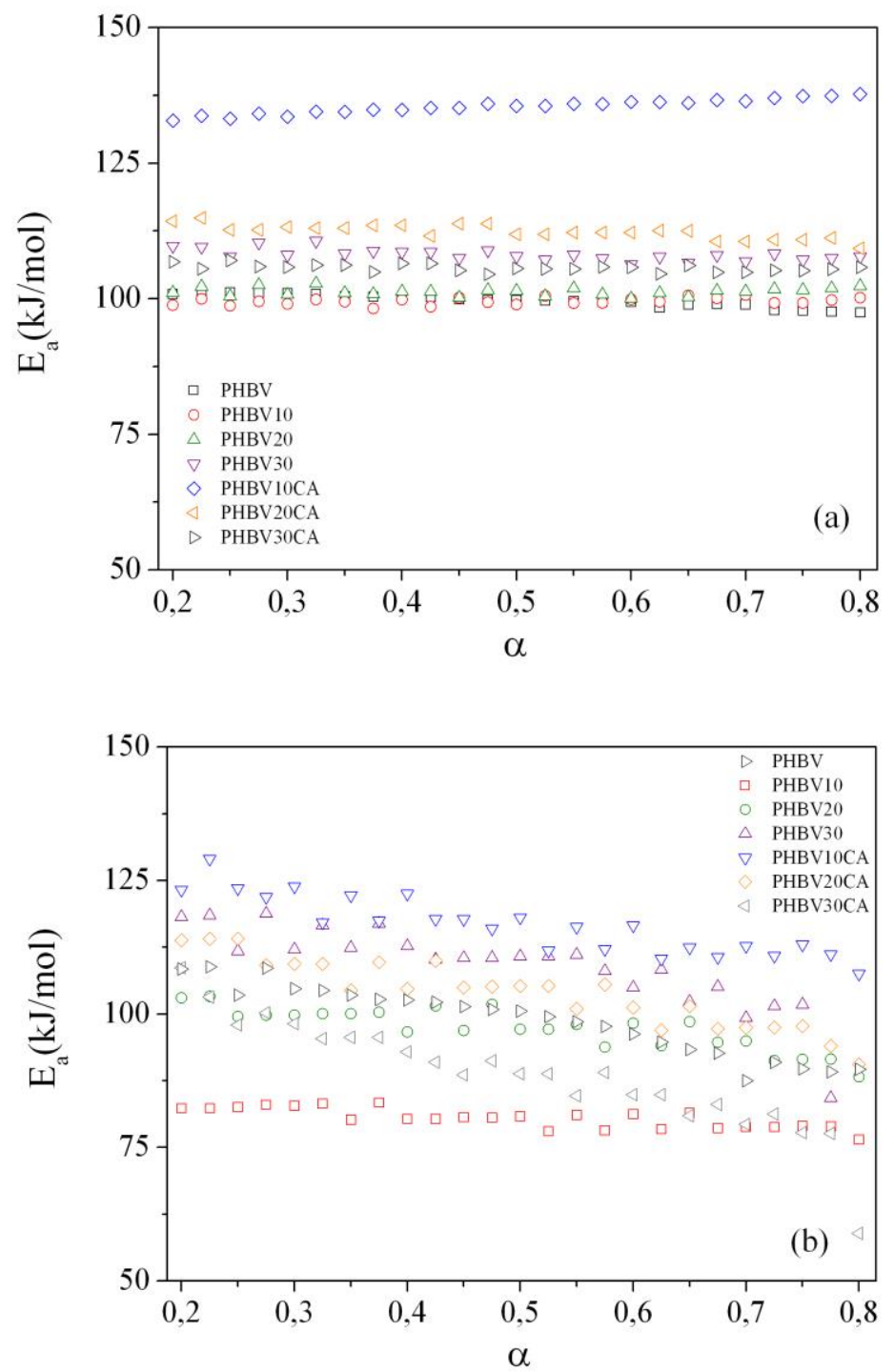

Fig. 4 Evolution of the activation energy according to KAS method (EaKAS) for all samples (range $\square \square=0.2-0.8$ ) under $\mathrm{Ar}(\mathrm{a})$ and $\mathrm{O}_{2}$ (b). Note: maximum error values below $10 \%$.

All the kinetic analysis were carried out in the range $\square=0.2-0.8$, where the main reactions of the process occurred. All the averaged values of all methods $\left(\mathrm{Ea}_{\mathrm{iso}}\right)$ for inert and oxidative conditions are gathered in Table 4. As it can be concluded from the values, the addition of fibres resulted in a decrease of Eaiso with the initial added fibres whereas it increased for the highest percentage of sisal. The highest values corresponded to the samples with CA in their composition. 
C. Moliner, J. D. Badia, B. Bosio, E. Arato, T. Kittikorn, E. Strömberg, R. Teruel-Juanes, M. Ek, S. Karlsson \& A. Ribes-Greus (2018) Thermal and thermo-oxidative stability and kinetics of decomposition of PHBV/sisal composites, Chemical Engineering Communications, 205:2, 226-237

As expected, the amount of energy required to run the decomposition of PHBV under Ar was higher in respect to that under $\mathrm{O}_{2}$ due to the increased reactivity of the system. These results are in accordance to the previous results in which biocomposites subjected to oxidative ambient started to decompose at lower temperatures.

In terms of recovery of energy, these values are lower than those for other commodity polymers like for example PET (Badia et al, 2013), indicating a lower energy requirement for the biocomposites respect to a traditionally used plastic showing more suitable conditions for energy valorisation processes.

\subsubsection{Master Plot Curves}

From a technological point of view, the apparent activation energy is related to the energy requirements of the thermo-chemical device. In order to complete the design of the reactor, the complete kinetic expression was evaluated and defined from the kinetic analysis of the biocomposites and the reduced Master Plot (MP) method.

MP are defined as the theoretical reference curves dependent on the kinetic model and, generally, independent of the kinetic parameters of the process. The comparison between the experimental values and these theoretical curves permits the obtaining of the appropriate kinetic model according to the best fitting obtained (Gotor et al, 2000).

The differential $\left(\mathrm{MP}_{\mathrm{f}}\right)$ and integral $\left(\mathrm{MP}_{\mathrm{g}}\right)$ curves were used and compared to experimental $\left(\mathrm{MP}_{\mathrm{e}}\right)$, choosing as the best model that which gave lower $\Omega$, as detailed elsewhere (Badia et al, 2012)

$$
\Omega=\sum_{i}^{\beta}\left[\left(\sum_{0}^{0.5}\left(M P_{f e}-M P_{f t}\right)^{2}+\left(\sum_{0.5}^{1}\left(M P_{g e}-M P_{g t}\right)^{2}\right]\right.\right.
$$

Fig. 5 shows the $\mathrm{MP}_{\mathrm{f}}$ and $\mathrm{MP}_{\mathrm{g}}$ curves (solid black lines: nucleation, solid grey lines: n-order, dashed lines: diffusion, circles: experimental data) corresponding to $\mathrm{PHBV}$ at $5{ }^{\circ} \mathrm{C} / \mathrm{min}$ for the composites: PHBV-Ar (a-b), PHBV30-Ar (c-d), PHBV30CA-Ar (e-f), PHBV30CA-O 2 (g-h). Similar plots were obtained for the rest of materials regardless the $\beta$ of analysis. 
C. Moliner, J. D. Badia, B. Bosio, E. Arato, T. Kittikorn, E. Strömberg, R. Teruel-Juanes, M. Ek, S. Karlsson \& A. Ribes-Greus (2018) Thermal and thermo-oxidative stability and kinetics of decomposition of PHBV/sisal composites, Chemical Engineering Communications, 205:2, 226-237
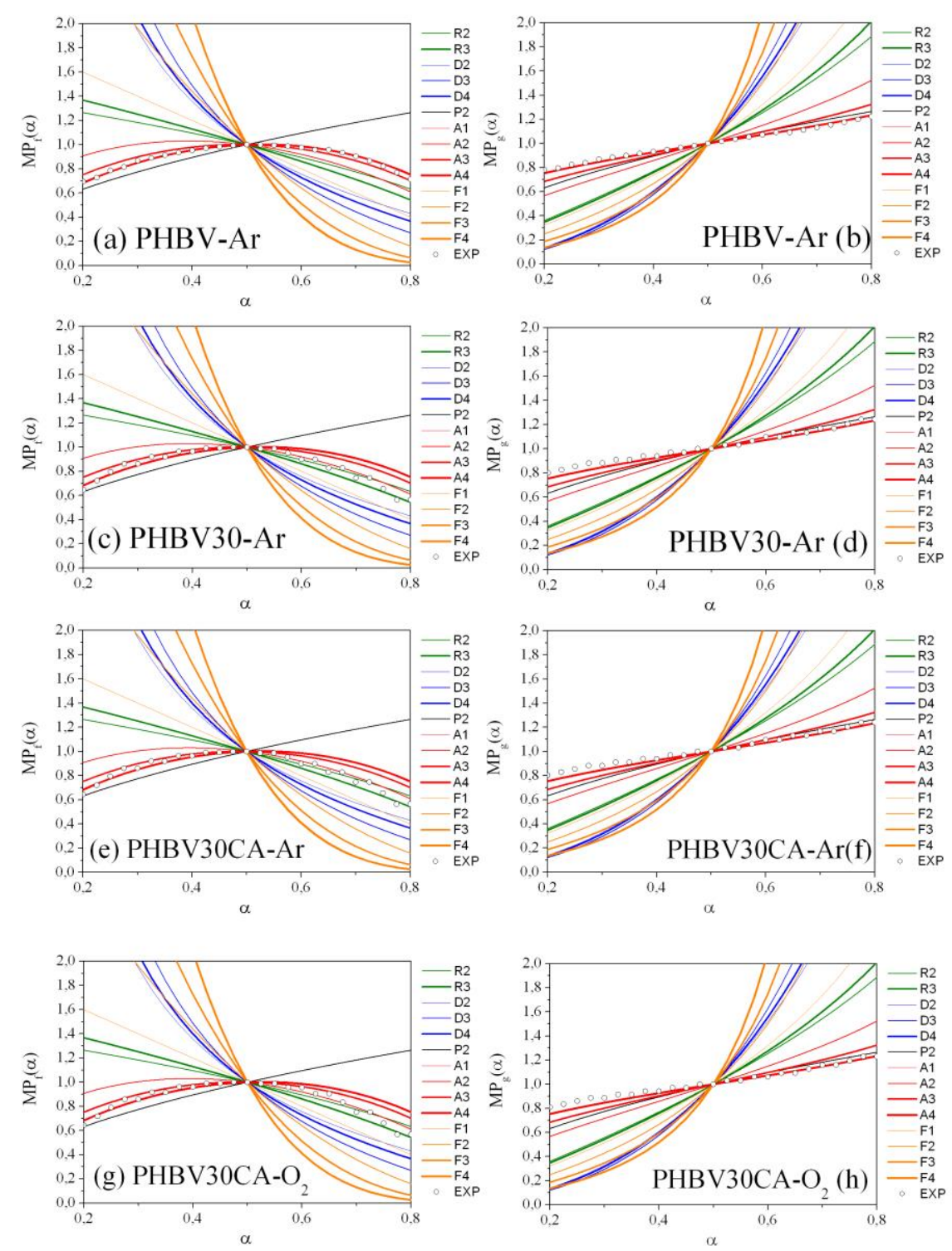

Fig. 5 Master plots based on the differential $\left(\mathrm{MP}_{\mathrm{f}}(\square)\right.$ and integral $\left(\mathrm{MP}_{\mathrm{g}}(\square)\right)$ forms of the kinetic model compared to the experimental data (circles): PHBV-Ar (a) and (b); PHBV30-Ar (c) and (d); PHBV30CA-Ar (e) and (f); PHBV30CA-O 2 (g) and (h). Kinetic Models: $\mathrm{D}_{\mathrm{n}}$ : diffusion controlled, (dashed lines), $A_{n}$ : nucleation and growth (solid black lines), $F_{n}$ : n-order reaction (solid grey lines), $\mathrm{R}_{\mathrm{n}}$ : reaction controlled (pointed lines). 
C. Moliner, J. D. Badia, B. Bosio, E. Arato, T. Kittikorn, E. Strömberg, R. Teruel-Juanes, M. Ek, S. Karlsson \& A. Ribes-Greus (2018) Thermal and thermo-oxidative stability and kinetics of decomposition of PHBV/sisal composites, Chemical Engineering Communications, 205:2, 226-237

Fig. 5 suggests that the thermal and thermo-oxidative decompositions of biocomposites could be explained by a $A_{n}$-nucleation type- kinetic function, which indicates the presence of active zones more chemically liable to thermal decomposition, which activate the formation and growth of gas bubbles in the melt. To analytically calculate the exact order of reaction (n), the minimisation method described in (Badia et al, 2012) was applied.

\subsubsection{Completion of the kinetic triplet: $n$ and pre-exponential factor}

The kinetic triplet defining the thermal processes was completed by obtaining the pre-exponential factor ( $\ln \mathrm{A})$ as the intercept of the equation and the exact order of reaction as a result of the accomplishment of the Coats-Redfern criterion (Eq. 3) according to which the points (x, y) should lie on the same straight line for all heating rates.

$$
\left[\ln \frac{\beta \cdot g(\alpha)}{T^{2}}\right]_{y}=\ln \frac{A_{\beta} \cdot R}{E a_{\beta}}+\frac{E a_{\beta}}{R} \cdot\left[\frac{1}{T}\right]_{x}
$$

with $g(\alpha)$ being the integral form of the kinetic model previously obtained and $\mathrm{R}$ the ideal gas constant $\left(8.31 \mathrm{~J} \mathrm{~mol}^{-1} \mathrm{~K}^{-1}\right)$.

Table 4 gathers the kinetic triplet corresponding to the main decomposition process for all the tested samples. The values of the pre-exponential factors A were higher in oxidative conditions, probably caused by the increase of temperature due to the increase of combustion reactions (Amutio et al, 2012).

Table 4. Kinetic triplet of PHBV biocomposites under inert and oxidative conditions

\begin{tabular}{|c|c|c|c|c|c|c|}
\hline \multirow[b]{2}{*}{ Conditions } & \multicolumn{2}{|r|}{ Eaiso } & \multicolumn{3}{|c|}{$\ln (A)$} & \multirow{2}{*}{$\begin{array}{c}\text { Kinetic model: An } \\
\mathbf{n}\end{array}$} \\
\hline & Material & (kJ/mol) & $\mathbf{e}$ & $\mathrm{A}\left(\mathrm{min}^{-1}\right)$ & $\mathbf{e}$ & \\
\hline \multirow{7}{*}{ Ar } & PHBV & 107 & $2,8 \%$ & 22,2 & $3,6 \%$ & 3,98 \\
\hline & PHBV10 & 101 & $6,2 \%$ & 21,7 & $6,3 \%$ & 5,50 \\
\hline & PHBV20 & 102 & $3,8 \%$ & 22,1 & $4,2 \%$ & 5,52 \\
\hline & PHBV30 & 109 & $2,4 \%$ & 24,1 & $2,0 \%$ & 4,50 \\
\hline & PHBV10CA & 137 & $7,2 \%$ & 29,6 & $8,2 \%$ & 4,24 \\
\hline & PHBV20CA & 113 & $9,1 \%$ & 24,5 & $9,3 \%$ & 7,30 \\
\hline & PHBV30CA & 107 & $8,6 \%$ & 23,8 & $9,7 \%$ & 6,41 \\
\hline \multirow{5}{*}{$\mathbf{O}_{2}$} & PHBV & 98 & $2,4 \%$ & 20,0 & $2.7 \%$ & 4,16 \\
\hline & PHBV10 & 83 & $8,0 \%$ & 17,4 & $8,7 \%$ & 5,98 \\
\hline & PHBV20 & 99 & $11,4 \%$ & 21,3 & $11,5 \%$ & 5,09 \\
\hline & PHBV30 & 106 & $9,9 \%$ & 26,9 & $10,0 \%$ & 3,94 \\
\hline & PHBV10CA & 118 & $8,4 \%$ & 25,4 & $9,0 \%$ & 5,18 \\
\hline
\end{tabular}


C. Moliner, J. D. Badia, B. Bosio, E. Arato, T. Kittikorn, E. Strömberg, R. Teruel-Juanes, M. Ek, S. Karlsson \& A. Ribes-Greus (2018) Thermal and thermo-oxidative stability and kinetics of decomposition of PHBV/sisal composites, Chemical Engineering Communications, 205:2, 226-237

$\begin{array}{lccccc}\text { PHBV20CA } & 105 & 15,6 \% & 22,8 & 15,2 \% & 5,37 \\ \text { PHBV30CA } & 90 & 12,2 \% & 23,0 & 10,1 \% & 6,89\end{array}$

The assigned model corresponded to the type An: nucleation and growth. The chemical mechanism has been reported in literature where the decomposition is found to be a mix of mechanisms comprising at least a thermal random $\beta$-elimination along with auto-accelerated transesterifications releasing crotonic and butenoic acids, or their derivatives (Fernandes et al, 2004).

\subsection{Operational inputs for energetic valorisation of PHBV/sisal biocomposites}

From an overall point of view, a minimum temperature of $240{ }^{\circ} \mathrm{C}$ and activation energy of 137 $\mathrm{kJ} / \mathrm{mol}$ would be necessary to be applied to carry out the reaction of pyrolysis of the PHBV and its biocomposites with sisal. For the case of oxidative reactions, lower temperatures and activation energies $\left(236^{\circ} \mathrm{C}\right.$ and $118 \mathrm{~kJ} / \mathrm{mol}$, respectively) would be required in order to perform the complete oxidation of the biocomposites, as a result of the lower stability of the polymeric matrix under oxidative conditions.

In comparison to other polymers, such as PET, which needs a minimum temperature of $380{ }^{\circ} \mathrm{C}$ and activation energy of $192 \mathrm{~kJ} / \mathrm{mol}$ in inert conditions and $280{ }^{\circ} \mathrm{C}$ and activation energy of $194 \mathrm{~kJ} / \mathrm{mol}$ under oxidative conditions (Badia et al. 2013), the use of these biocomposites would decrease the requirements of energy valorisation operations. In addition, since the conditions of the biocomposites are comparable and even lower respect to other plastic materials, no further modifications would be required to the currently used technologies if PHBV biocomposites were used as feedstock.

Furthermore, since similar parameters could be implemented for the valorisation of both PHBV and PHBV/sisal biocomposites, even both under inert and oxidative conditions, this fact would remarkably permit working in a joint and continuous way, as well as reduce the cost of investing in other technologies. 
C. Moliner, J. D. Badia, B. Bosio, E. Arato, T. Kittikorn, E. Strömberg, R. Teruel-Juanes, M. Ek, S. Karlsson \& A. Ribes-Greus (2018) Thermal and thermo-oxidative stability and kinetics of decomposition of PHBV/sisal composites, Chemical Engineering Communications, 205:2, 226-237

\section{Conclusions}

An accurate methodology evaluated the suitability and optimal operational parameters of the thermal and thermo-oxidative decompositions of PHBV/sisal biocomposites. The trigger of decomposition was more sensitive to oxidative conditions. An improvement of the thermal and thermo-oxidative stability of PHBV with the addition of sisal was observed in all cases. The presence of CA slightly increased the thermal stability of all biocomposites.

The same kinetic law following the kinetic model $A_{n}$ (nucleation and growth) was found valid with little adjustments for all the biocomposites at both inert and oxidative conditions, facilitating the energy valorisation regardless their composition.

The minimum temperature of reaction and activation energy to ensure the decomposition of all the biocomposites were obtained for pyrolysis and complete oxidation processes. The parameters obtained from both processes did not vary in great measure with the addition of fibres or coupling agent to the polymeric matrix indicating that a joint energy valorisation could be carried out. The obtained results will be useful for the correct tuning of the operational conditions of a device performing the joint studied thermo-chemical reactions.

\section{Acknowledgements}

The Spanish Ministry of Economy and Competitiveness and European Regional Development Funds are acknowledged for the projects POLYCELL (ENE2014-53734-C2-1-R) and TETRA-SEC (UPOV13-3E-1947). Generalitat Valenciana is thanked for the APOSTD/2014/041 for J.D. Badia. The financial support given by the Prince of Songkla University and KTH Royal Institute of Technology is gratefully acknowledged. 


\section{References}

Akahira T., Sunose T. (1971) Trans.Joint Convention of Four Electrical Institutes, Paper N.246, Research Report/Chiba Institute of Technology. Scientific Technology 16 22-31.

Al-Salem, S.M., Lettieri, P., Baeyens, J. (2009) Recycling and recovery routes of plastic solid waste (PSW): a review. Waste management 29 2625-2643.

Amutio M., Lopez G., Aguado R., Artetxe M., Bilbao J., Olazar M. (2012) Kinetic study of lignocellulosic biomass oxidative pyrolysis, Fuel 95 305-311.

Badía JD, Santonja-Blasco L, Moriana R, Ribes-Greus A. (2010) Thermal analysis applied to the characterization of degradation in soil of polylactide: II. On the thermal stability and thermal decomposition kinetics. Polym Degrad Stab 95(11) 2185-91.

Badia J.D., Stromberg E., Ribes-Greus A., Karlsson S.(2011a) A statistical design of experiments for optimizing the MALDI-TOF-MS sample preparation polymers. An application in the assessment of the thermo-mechanical degradation mechanisms of poly (ethylene terephthalate), Analytica Chimica Acta 692 85-95.

Badía JD, Strömberg E, Ribes-Greus A, Karlsson S. (2011b) Assessing the MALDI-TOF MS sample preparation procedure to analyze the influence of thermo-oxidative ageing and thermomechanical degradation on poly (lactide). European Polymer Journal 47(7) 1416-28.

Badia J.D., Santonja-Blasco L., Martinez-Felipe A., Ribes-Greus A. (2012a) Reprocessed polylactide: Studies of thermo-oxidative decomposition, , Bioresource Technology 114 622-628.

Badia JD, Santonja-Blasco L, Martinez-Felipe A., Ribes-Greus A. (2012b) A methodology to assess the energetic valorization of bio-based polymers from the packaging industry: pyrolysis of reprocessed polylactide, Bioresource Technology $111468-475$.

Badia J.D., Martinez-Felipe A., Santonja-Blasco L., Ribes-Greus A. (2013) Thermal and thermooxidative stability of reprocessed poly(ethylene terphthalate), Journal of Analytical and Applied Pyrolysis 99 191-202.

Badia JD, Kittikorn T, Strömberg E, Santonja-Blasco L, Martínez-Felipe A, Ribes-Greus A, Ek M, Karlsson S.(2014) Water absorption and hydrothermal performance of PHBV/sisal biocomposites. Polym. Degrad. Stab. 108 166-174. 
C. Moliner, J. D. Badia, B. Bosio, E. Arato, T. Kittikorn, E. Strömberg, R. Teruel-Juanes, M. Ek, S. Karlsson \& A. Ribes-Greus (2018) Thermal and thermo-oxidative stability and kinetics of decomposition of PHBV/sisal composites, Chemical Engineering Communications, 205:2, 226-237

Bledzki A.K., Jaszkiewicz A. (2010) Mechanical performance of biocomposites based on PLA and PHBV reinforced with natural fibres, Composites Science and Technology 70 1687-1696.

Fernandes E. G, Pietrini, M, Chiellini E. (2004) Bio-based polymeric composites comprising wood flour as filler, Biomacromolecules 5 (4)1200-5.

Flynn J.H., Wall L.A., (1966) A quick, direct method for the determination of activation energy from thermogravimetric data, Journal of Polymer Science 4 323-342.

Gil-Castell O, Badia JD, Kittikorn T, Strömberg E, Martínez-Felipe A, Ek M, Karlsson S, RibesGreus A. (2014) Hydrothermal ageing of polylactide/sisal biocomposites. Studies of water absorption behaviour and physico-chemical performance. Polym Degrad Stab 108 212-222.

Gotor F.J., Criado J.M., Malek J., Koga N. (2000) Kinetic analysis of solid-state reactions: the universatility of master plots for analysing isothermal and non-isothermal experiments. Journal of Physical Chemistry A 104 10777-10782.

Kowalczuk M. M., Kurcok P., Kawalec M., Sobota M., Michalak M., Kwiecien M. (2014) New generation of the polymeric packaging materials susceptible to organic recycle. Chemik 68 8, 679691.

Lu J., Wu Q., MacNabb H.S.Jr, (2000) Chemical coupling in wood fiber and polymer composites: a review of coupling agents and treatments. Wood and Fiber Science 32 (1) 88-104.

Moliner C., Bosio B. Arato E., Ribes A. (20165) Thermal and thermo-oxidative characterization of rice straw for its use in energy valorization processes. Fuel 180 71-79.

Monteiro S., Calado V., Rodriguez R., Margem F. (2012) Thermogravimetric behavior of natural fibers reinforced polymer composites-an overview. Materials Science \& Engineering A 557 17-28.

Moran J.I., Vera, Alvarez A., Cyras P.(2008) Extraction of cellulose and preparation of nanocellulose from sisal fibers. Cellulose 15 149-159.

Ozawa T. (1970) Kinetic analysis of derivative curves in thermal analysis. Journal of thermal analysis 2301.

Rydz J., Sikorska W., Kyulavska M., Christova D. (2015) Polyester based bio-degradable polymers as environmentally friendly materials for sustainable development. Int. J. Mol. Sci.16 564-596.

Vyazovkin S. (1997) Advanced isoconversional method, Journal of thermal analysis 49 1493-1499. 
C. Moliner, J. D. Badia, B. Bosio, E. Arato, T. Kittikorn, E. Strömberg, R. Teruel-Juanes, M. Ek, S. Karlsson \& A. Ribes-Greus (2018) Thermal and thermo-oxidative stability and kinetics of decomposition of PHBV/sisal composites, Chemical Engineering Communications, 205:2, 226-237

Weng Y.X., Wang Y., Wang X.L., Wang Y.Z. (2010) Biodegradation behaviour of PHBV films in a pilot-scale composting condition, Polymer Testing, 29 579-587. 
C. Moliner, J. D. Badia, B. Bosio, E. Arato, T. Kittikorn, E. Strömberg, R. Teruel-Juanes, M. Ek, S. Karlsson \& A. Ribes-Greus (2018) Thermal and thermo-oxidative stability and kinetics of decomposition of PHBV/sisal composites, Chemical Engineering Communications, 205:2, 226-237

\section{Annex. Open access policies}

Buscar - Políticas de copyright de las editoriales y autoarchivo nicio - Buscar · Revistas - Editoriales · FAQ - Sugerir · Sobre Se ha encontrado una revista que coincide con los criterios de búsqueda:: chemical engineering communications

\begin{tabular}{|c|c|}
\hline \multicolumn{2}{|r|}{$\begin{array}{l}\text { Revista: Chemical Engineering Communications (ISSN: 0098-6445, ESSN: 1563-5201) } \\
\text { RoMEO: This is a RoMEO green joumal }\end{array}$} \\
\hline RoMEO: & 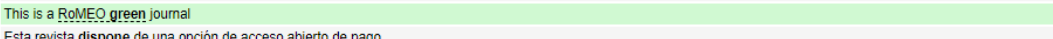 \\
\hline \multicolumn{2}{|c|}{ Pre-print del autor: $\checkmark$ el autor puede archivar la versión pre-print (ie la versión previa a la revisión por pares) } \\
\hline \multicolumn{2}{|c|}{ Post-print del autor: $\checkmark$ el autor puede archivar la versión post-print (ie la versión final posterior a la revisión por pares) } \\
\hline \multicolumn{2}{|c|}{ Versión de editor/PDF: $\boldsymbol{X}$ el autor no puede archivar la versión del editor/PDF } \\
\hline Condiciones generales: & 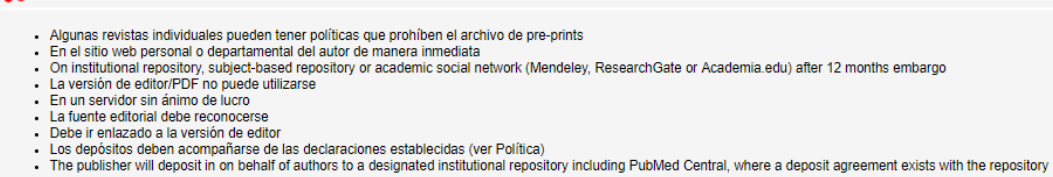 \\
\hline OA mandatorio: & (Esperando información) \\
\hline \multirow{2}{*}{$\begin{array}{r}\text { Open Access de pago: } \\
\text { Notas: }\end{array}$} & Taylor \& Francis Open Select - 500 journals \\
\hline & $\begin{array}{l}\text { STM: Science, Technology and Medicine } \\
\text {. Publisher last contacted on 25//33/2014 }\end{array}$ \\
\hline \multirow{2}{*}{\multicolumn{2}{|c|}{ Copyright: Pollica }} \\
\hline \multirow{2}{*}{\multicolumn{2}{|c|}{ 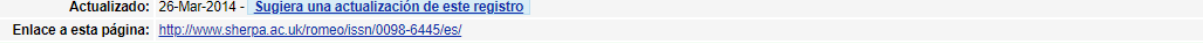 }} \\
\hline & \\
\hline \multicolumn{2}{|c|}{ Publicado por: Taylor \& Francis: STM, Behavioural Science and Public Health Titles - Green Policies in RoMEO } \\
\hline $\begin{array}{l}\text { Este es el } \\
\text { Toda la in }\end{array}$ & $\begin{array}{l}\text { resumen para las políticas de la revista, default y los cambios o excepciones a menudo pueden ser negociados por los autores. } \\
\text { nformación es correcta según nuestro mejor conocimiento, pero en ningún caso puede ser utilizado como un documento legal. }\end{array}$ \\
\hline
\end{tabular}

